\title{
Harmonization of summaries of product characteristics (SmPCs) of drugs with the same active ingredients: an evaluation of SmPCs of the most frequently prescribed active substances
}

\author{
Maximilian Gahr ${ }^{1} \mathbb{D} \cdot$ Bernhard J. Connemann $^{1} \cdot$ Rainer Muche $^{2} \cdot$ René Zeiss $^{1} \cdot$ Almuth Wolf $^{1}$
}

Received: 23 June 2021 / Accepted: 26 August 2021 / Published online: 27 October 2021

(c) The Author(s) 2021

\begin{abstract}
Purpose In aut-idem or generic substitution, discrepancies between summaries of product characteristics (SmPCs) referring to the same active substance (AS) may cause difficulties regarding informed consent and medical liability. The qualitative and quantitative characteristics of such discrepancies are insufficiently studied, impeding harmonization of same-substance SmPCs and compromising safe drug treatment.

Methods SmPCs of the one hundred most frequently prescribed ASs in Germany were analyzed for discrepancies in the presentation of indications (Inds) and contraindications (CInds). Inclusion and exclusion criteria of drugs/SmPCs were chosen according to the standards of the aut-idem substitution in Germany.

Results According to the study protocol, we identified 1486 drugs, of which 1426 SmPCs could be obtained. $41 \%$ respectively $65 \%$ of the ASs had same-substance SmPCs that differed from the respective reference SmPC in the number of listed Inds respectively CInds. The number of listed Inds/CInds varied considerably between same-substance SmPCs with maximum ranges in Inds of 7 in amoxicillin, and in CInds of 11 in lisinopril. Many ASs had large proportions (>50\%) of associated same-substance SmPCs that differed from the respective reference SmPC. A considerable proportion of ASs had same-substance SmPCs with formal and content-related differences other than the discrepancy in the number of Inds/CInds. Conclusion This evaluation of same-substance SmPCs shows a clear lack of harmonization of same-substance SmPCs. Considering that generic substitution has become the rule and that physicians usually do not know which drug the patient receives in the pharmacy, these discrepancies raise several questions, that require a separate legal evaluation.
\end{abstract}

Keywords Aut-idem · Generic drug · Generic substitution · Package insert · Pharmacovigilance $\cdot$ Prescribing information

\section{Introduction}

For economic reasons, the supply with generic medication is politically preferred in most countries. In the European Union, different national regulatory frameworks exist to ensure the preferential prescription and/or the dispensing of generic drugs. In Germany, the so-called "aut-idem substitution" which is the term for the legal,

Maximilian Gahr

maximilian.gahr@uni-ulm.de

1 Department of Psychiatry and Psychotherapy III, University Hospital of Ulm, Leimgrubenweg 12-14, 89075 Ulm, Germany

2 Institute of Epidemiology and Medical Biometry, University of Ulm, Schwabstr. 13, 89075 Ulm, Germany regulatory and operative framework concerning generic substitution in Germany obliges pharmacists to dispense a same-substance medication of the lower third of the price range, if the respective drug is prescribed at the expense of the statutory health insurance and the responsible physician does not explicitly exclude the substitution of the prescribed product by a generic drug [1]. In Germany, exclusion of the aut-idem or generic substitution constitutes an additional expense and, in addition, requires an individual justification by the physician (which is usually not accepted by the health insurance companies). Therefore, the aut-idem or generic substitution has become the rule in Germany [2]. However, reduced efficacy and tolerability and differences in bioequivalence, particularly regarding psychoactive and antiepileptic drugs were found in association with switching from brand-name to generic medication (resp. aut-idem substitution) and vice 
versa and/or switching generic drugs [3-9]. Moreover, discrepancies between SmPCs of drugs with the same active ingredients were found in several studies [10-13], although regulations of the European Medicines Agency (EMA) provide that the content of summaries of product characteristics (SmPCs, which are the European counterpart of the US prescribing information) of generic drugs "... should be in all relevant aspects consistent with that of the reference medicinal product except for indications or dosage form still covered by patent law..." [14] and the EMA and the Committee for Medicinal Products for Human Use (CHMP) are working with harmonization of SmPCs (by post-authorisation referral procedures [15] and guidelines [16]). These discrepancies between samesubstance SmPCs may refer to actual differences between the corresponding same-substance products (regarding regulatory aspects as approved indications, but also pharmacologic aspect as excipients, additives, and carriers of the active substance, available strengths, dosage form, appearance and size of the drug, bioavailability, galenical properties, etc.) and/or may be self-referential in terms of discrepancies in form and content of SmPCs without clear reference to possible regulatory and/or pharmacologic/galenic differences between the corresponding same-substance products. Since the physician usually does not know, which generic drug is dispensed in the pharmacy, the differences between same-substance drugs and the discrepancies between same-substance SmPCs may cause difficulties regarding informed consent and may have implications for medical liability. Qualitative and quantitative characteristics of discrepancies between same-substance SmPCs are not sufficiently known, which impedes harmonization of same-substance SmPCs and compromises safe drug treatment. Therefore, we have analyzed selected paragraphs of the SmPCs of the most frequently prescribed active substances in Germany regarding type and extent of discrepancies between samesubstance SmPCs.

\section{Ethical approval}

No personal data were used in the present study. According to the guidelines and regulations of the local ethics committee (Ulm University) no ethical approval is necessary in such cases.

\section{Period of data collection}

The data were collected from August 3, 2020, until October 27,2020 . Data regarding over-the-counter drugs were collected from January 26, 2021, until February 28, 2021.

\section{Selection of active substances}

The one hundred most frequently prescribed active substances in Germany in 2018 were included and ranked according to the number of annual prescriptions. ${ }^{1}$ Active substances and quantities of annual prescriptions were identified by the "Arzneiverordnungs-Report 2019" (AVR) [2]. The AVR is an annual scientific document published since the year 1985 and contains data, costs, and analyses of drug prescriptions of the previous year, prescribed at the expense of the statutory health-insurance companies in Germany. Over-the-counter drugs that are prescribed at the expense of the statutory health-insurance companies in Germany are also considered in the AVR.

Excluded active substances (see next paragraph) were replaced by subsequent active substances, and the list of active substances was extended accordingly by adding the 101st, 102nd ranked active substance, etc., until the list contained one hundred active substances.

\section{Inclusion and exclusion criteria of drugs respectively SmPCs}

As every SmPC constantly refers to a specific medicinal product and not to an active substance, the inclusion and exclusion criteria, which are explained in the following, always refer to an individual pair of a drug and the corresponding SmPC.

Inclusion and exclusion criteria of drugs or SmPCs were chosen according to the standards of the aut-idem substitution in Germany: This implies that (1) (according to part B of the annex VII to paragraph $\mathrm{M}$ of the drug directive of the Federal Joint Committee (G-BA), which constitutes the so-called "Substitutionsausschlussliste") [17]) specific active substances and/or combinations of active substances are a priori explicitly excluded from the generic substitution (in our study levothyroxine sodium and the combination of levothyroxine and potassium iodate were excluded), and (2) only drugs that are identical to the prescribed drug regarding strength and package size, (3) only drugs that are approved for the treatment of at least one similar disorder, and (4) only drugs that feature the same or an exchangeable dosage form may be dispensed as aut-idem substitutes in the pharmacy. In order to exclude "real" drug-related differences as reasons for discrepancies between same-substance SmPCs, only same-substance products with identical strength, package size and dosage form were included. Therefore, the most

\footnotetext{
${ }^{1}$ In the AVR, the annual prescriptions referring to an active substance refer to the number of annual prescriptions of a drug with the respective active substance in any of the three available package sizes (N1, N2 or N3).
} 
frequently prescribed strength of an active substance or product was identified by the AVR and used for further data acquisition. To further harmonize the characteristics of the included SmPCs, same-substance SmPCs referring to the most frequently prescribed package size of an active substance (identified by the AVR) were included. There are three normed package sizes in Germany: N1 (small package size: 16-24 units), N2 (moderate: 45-55 units), and N3 (large: 95-100 units). Apart from seven active substances/ingredient combinations (azithromycin, colecalciferol, dexamethasone/gentamicin, fosfomycin, ivy leaves, paracetamol and xylometazoline) (here, the most frequently prescribed package size was N1) the most frequently prescribed package size was N2. Finally, based on the data obtained via the German online portal for drug information of the federal and state government ("PharmNet.Bund"; for further details see next paragraph $)^{2}$ the dosage form with the most same-substance drugs was selected (in most active substances oral dosage forms) and used for further data acquisition. Only products that were marketable and approved in Germany during the period of the data collection were included. Parallel imported and reimported drugs were excluded as these products are subject to a simplified or-in cases of Europe-wide marketing authorisation-no marketing authorisation procedure, which implies that SmPCs of those products are merely translations of the SmPC of the original product. Products, which are manufactured according to officially normed standard formulations (so-called "Standardzulassungen") and therefore exempt from the marketing authorisation procedure were also excluded. (These products are predominantly only available in pharmacies as store brands, and their SmPCs were frequently unavailable). Homeopathic medicinal products were excluded. Finally, if only one same-substance product was identified according to the mentioned inclusion and exclusion criteria, the respective active substance (ambroxol, physiological saline solution, noscapine, iron (II) glycine sulfate, imidazole/triazole combined with corticosteroids) was excluded.

\section{Identification of products and acquisition of SmPCs}

The German online portal for drug information of the federal and state government ${ }^{3}$ ("PharmNet.Bund") was used for identification of the included products by using the name of the active substances identified by the AVR and the corresponding code of the Anatomical

\footnotetext{
2 Based on the data obtained from "PharmNet.Bund", the dosage form with the most same-substance drugs was selected.

${ }^{3}$ See: https://www.pharmnet-bund.de/static/de/index.html
}

Therapeutic Chemical (ATC) Classification System [18]. The portal makes drug-related data of the higher German federal authorities centrally and transparently available to the public. In addition, it provides applications for communication, authorisation, and registration of drug-related data to public authorities and pharmaceutical manufacturers. Furthermore, an integrated online database and search tool ("ArzneimittelInformationssystem" [AMIS $]^{4}$ ) provides drug information as name of the drug, dosage form, authorisation holder and number, information regarding marketability, SmPC and patient package insert, etc. free of charge. The content of this database is maintained and daily updated by the Federal Institute for Drugs and Medical Devices, the Paul Ehrlich Institute, and the Federal Office of Consumer Protection and Food Safety. Following identification of included products by AMIS according to the above-mentioned inclusion and exclusion criteria, the corresponding SmPCs were obtained directly in AMIS or by using the online portals "Rote Liste"5 and/or "Gelbe Liste". ${ }^{6}$ If the SmPCs were not available by searching one of these online portals, the respective SmPC was requested directly by the manufacturer by email. ${ }^{7}$ In order to exclude discrepancies between same-substance SmPCs due to differing update status of SmPCs, all same-substance SmPCs were obtained, respectively requested within one day.

\section{Analysis of SmPCs and examined parameters- primary analysis (number of Inds and CInds)}

The number of indications (Ind) and contraindications (CInd) were analyzed. Therefore, the standardized

\footnotetext{
${ }^{4}$ From March 19, 2020 until August 30, 2020 the data of AMIS was migrated to a new database ("Arzneimittel-Antrags-Datenbank" [AmAnDa]) that features a new user interface ("ArzneimittelInformationssystem certified edition" [AMIce]). During this period, AMIS data with the update status of March 19, 2020 were available. From August 31, 2020 on, AmAnDa was available and old AMIS data as of March 19, 2020 is still available. Therefore, during the period of data collection of this study (August 3, 2020 until October 27, 2020) we used AMIS data until August 30, 2020 and AmAnDa data from August 31, 2020 on. As a consequence, during August 3 until August 30, 2020 we obtained data with the update status of March 19, 2020.

5 The "Rote Liste" (see: https://rote-liste.de) is the German highestcirculation drug compendium (available online and print) which contains short information regarding human medicines approved in Germany (e.g., SmPCs and package inserts) and certain medical devices.

6 The "Gelbe Liste" (see: https://gelbe-liste.de) is a German drug compendium that is available online and print. It provides drug information as areas of application of a drug, contraindications, drug interactions, side effects, dosing, costs, SmPCs, etc.

7 Sixty out of 1486 identified products/SmPCs could not be obtained with either of the mentioned acquisition strategies.
} 
paragraphs of the SmPCs "4.1 Indications" and "4.3 Contraindications" of each included SmPC were investigated and the number of listed Inds and CInds was counted and documented. In the primary evaluation of the Inds and CInds apparent discrepancies in the number of Inds and CInds due to formal discrepancies between samesubstance SmPCs in the presentation of Inds and CInds were not considered. Therefore, the primary evaluation strictly focused the content of the respective paragraph and disregarded formal discrepancies. Discrepancies in content were decisive for the identification of discrepancies in the number of Inds and CInds and discrepancies in formal aspects were not considered in this part of the analysis. ${ }^{8}$ In principle, only absent or additional Inds/ CInds in the respective paragraph led to identification of discrepancies in the number of Inds/CInds. For every active substance, the reference SmPC for the identification of absent or additional Inds/CInds was the most frequent type of a same-substance SmPC. (The reference SmPC thus represents the largest group of harmonized same-substance SmPCs relating to all SmPCs referring to the same active substance.)

Groups of SmPCs referring to the same active substance were created and the associated numbers of Inds and CInds were compared. To describe the degree of harmonization of a group of same-substance SmPCs the range ( $=$ difference between maximum and minimum value) of the number of Inds and CInds of the associated same-substance SmPCs was calculated. In addition, the proportion of same-substance SmPCs with differing numbers of Inds/CInds was calculated by the number of discrepant SmPCs divided by the total number of SmPCs referring to the respective active substance. For every

\footnotetext{
${ }^{8}$ For instance, in some same-substance SmPCs certain CInds are listed as separate points, whereas in other SmPCs relating to the same active substance these CInds are shown under one point. In these cases, the number of the listed CInds was evaluated as identical (="No quantitative discrepancies in the number of Inds/CInds found"). Other, rather formal discrepancies, which were also not determined as discrepancies, referred to differing formulations (e.g. arterial hypertonia vs. hypertension). Furthermore, also the presence vs. absence of specifications of Inds/CInds (e.g. "concomitant use of drugs that are known to cause prolongation of the QT-interval" vs. "concomitant use of drugs that are known to cause prolongation of the QT-interval. Concomitant use of pimozide.") were not evaluated as discrepancies in the number of Inds/CInds. Finally, it has to be considered that CInds that refer to pregnancy and lactation are usually listed in a separate standardized paragraph (4.6 Fertility, pregnancy and lactation); however, in some SmPcs, CInds referring to pregnancy and lactation are (additionally) listed under point 4.2 (CInds) and in other SmPCs referring to the same active substance these CInds are listed only under point 4.6; this was evaluated as a discrepancy in the number of contraindications in the present study. However, such duplications of information in SmPCs were specifically evaluated and indicated in the secondary analysis.
}

active substance, the reference SmPC for the qualitative and quantitative evaluation of the Inds/CInds was the most frequent type of a same-substance SmPC.

\section{Analysis of SmPCs and examined parameters- secondary analysis (other aspects)}

In the secondary analysis, other discrepancies between samesubstance SmPCs, e.g., regarding formal and/or contentrelated aspects, were analyzed. The reference SmPC for the identification of such discrepancies was the most frequent type of a same-substance SmPC respectively the SmPC that represented the majority of harmonized same-substance SmPCs. We defined five types of discrepancies. These are elucidated in Table 1.

\section{Statistical analysis}

All analyses were performed with Microsoft Excel (version 2019).

\section{Results}

\section{Basic aspects}

According to the study protocol we identified 1486 drugs (referring to 100 active substances), of which 1426 SmPCs could be obtained. Sixty SmPCs could not be obtained with any of the mentioned data acquisitions methods. Seven active substances/combinations of active substances had to be excluded according to the inclusion and exclusion criteria. ${ }^{9}$ The most frequently prescribed dosage forms of the identified 100 most frequently prescribed active substances were oral (film-coated tablet: $34 \%$; tablet: $25 \%$; hard capsule: $7 \%$; sustained-release tablet: $5 \%$; powder/ granulate for oral solution: $3 \%$; oral drops: $2 \%$; oral solution: $1 \%$; soft capsule: $1 \%$ ), followed by powder/suspension for inhalation (7\%), solutions for injection (5\%), eye drops (3\%), cream (3\%), nasal drops (2\%), suppositories $(1 \%)$, and transdermal patches (1\%). Table 2 demonstrates the

\footnotetext{
${ }^{9}$ Excluded active substances/combinations of active substances, reasons for exclusion, and ranking in the list of the most frequently prescribed active substances: levothyroxine sodium (ranking position 3), combination of levothyroxine and potassium iodate (ranking position 29) (both active substances were excluded as they are listed in the so called "Substitutionsausschlussliste"), imidazole/triazole combined with corticosteroids (ranking position 56), physiological saline solution (ranking position 76), noscapine (ranking position 90), ambroxol (ranking position 99), iron (II) glycine sulfate (ranking position 102) (the last five active substances were excluded as only one same-substance product was identified according to the study protocol).
} 
Table 1 Definition of types of discrepancies between same-substance SmPCs other than differences in the number of Inds and CInds

\begin{tabular}{|c|c|}
\hline Type of discrepancy & Definition of the type of discrepancy \\
\hline Type A & $\begin{array}{l}\text { According to the evaluation protocol no discrepancies in the number of Inds and CInds, but content-related differences } \\
\text { were found (e.g. an Ind/CInd of the reference SmPC is replaced by a different Ind/CInd in one or more SmPCs referring } \\
\text { to the same substance). }\end{array}$ \\
\hline Type B & $\begin{array}{l}\text { Discrepancy in number and content of Inds/CInds was found, e.g., some Inds/CInds of the reference SmPC are not listed } \\
\text { and replaced by more and different Inds/CInds. The quantitative extent of the overall discrepancy between the respective } \\
\text { same-substance SmPCs is therefore underestimated by only using the range. }\end{array}$ \\
\hline Type C & $\begin{array}{l}\text { Discrepancy in the number of CInds was found. (This type of discrepancy was found only in the presentation of CInds.) } \\
\text { The respective CInds are not listed in the respective paragraph (4.3), however are shown in another paragraph of the } \\
\text { SmPC (e.g. } 4.4 \text { or } 4.6 \text { ) completely (type } C^{1} \text { ) or incompletely (type } C^{2} \text { ), and with identical (type } C^{a} \text { ) or different content } \\
\text { (type } C^{b} \text { ). Type } C^{a+b} \text { was used to describe SmPCs with > } 1 \text { CInds absent in paragraph } 4.3 \text { and listing of some absent } \\
\text { CInds in identical and some CInds in different wording in another paragraph. }\end{array}$ \\
\hline Type D & $\begin{array}{l}\text { Discrepancy in the number of CInds was found. (This type of discrepancy was found only in the presentation of CInds.) } \\
\text { This discrepancy is due to the following: CInds that are listed in paragraphs other than } 4.3 \text { in all same-substance } \\
\text { SmPCs are additionally listed in paragraph } 4.3 \text { in some SmPCs. (This discrepancy is due to the additional listing of } \\
\text { CInds in paragraph } 4.3 \text { in some SmPCs, whereby these CInds are listed in all same-substance SmPCs in a paragraph } \\
\text { other than 4.3.) }\end{array}$ \\
\hline Combined type & Two types of discrepancies (A, B, C or D) are found in one SmPC. This is expressed as "type $\mathrm{x}+\mathrm{y}$ ". \\
\hline
\end{tabular}

Ind indication, $C$ Ind contraindication, SmPC summary of product characteristics

included active substances, the associated annual prescriptions, dosage forms, and strengths.

\section{Discrepancies in the number of Inds (primary analysis)}

Discrepancies between same-substance SmPCs in the number of listed Inds were found in $41(41 \%)$ of included active substances. The largest ranges between minimum and maximum number of Inds of same-substance SmPCs were found in amoxicillin (range $=7$ ), ibuprofen (range $=5$ ), and allopurinol, clopidogrel, ramipril, escitalopram, sertraline, and sulfamethoxazole/trimethoprim (in each case range $=4$ ). The largest proportion of SmPCs with a divergent number of Inds were found in sulfamethoxazole/trimethoprim $(62.5 \%),{ }^{10}$ mometasone (50\%), formoterol (50\%), bisoprolol (47.4\%), valproic acid (46.7\%), macrogol (46.2\%), levodopa/benserazide $(42.9 \%)$, hydrochlorothiazide $(38.9 \%)$, betamethasone $(37.5 \%)$, citalopram (36\%), codeine $(33.3 \%)$, amitriptyline $(25 \%)$, ciprofloxacin (23.5\%), amoxicillin, budesonide, and salbutamol (in each case 20\%). Table 3 demonstrates number of evaluated same-substance SmPCs, number of listed Inds (and mean, median, maximum and minimum number of Inds, range, and standard deviation),

\footnotetext{
10 This is an example for a group of included same-substance SmPCs with less than half harmonized SmPCs: Eight SmPCs referring to sulfamethoxazole/trimethoprim were evaluated. Three harmonized (=identical form and content) SmPCs were identified. The remaining five SmPCs featured a "unique" presentation of Inds.
}

and absolute and relative frequencies of drugs/SmPCs with differing numbers of Inds.

\section{Other formal and content-related discrepancies in the presentation of Inds (secondary analysis)}

A discrepancy of type A was found in one SmPC (1\%) (referring to the ingredient combination levodopa/benserazide), and a discrepancy of type B was found one in each SmPC of the following three substances: amoxicillin, amoxicillin/clavulanic acid, and sulfamethoxazole/trimethoprim (3\%). A discrepancy of type C and D was not found in the presentation of Inds (see Table 4).

\section{Discrepancies in the number of Clnds (primary analysis)}

Discrepancies between same-substance SmPCs regarding the number of listed CInds were found in 65 (65\%) of included active substances. The largest ranges between minimum and maximum number of CInds of samesubstance SmPCs were found in lisinopril (range $=11$ ), hydrochlorothiazide (range $=9)$, torasemide $($ range $=8$ ), carvedilol (range $=7$ ), betamethasone, formoterol, lorazepam, metoprolol, oxycodone (each range $=6$ ), and mometasone (range $=4$ ). The largest proportions of same-substance SmPCs with a divergent number of CInds were found in carvedilol $(71.4 \%)$, torasemide $(61.5 \%)$, mometasone $(66.7 \%)$, betamethasone $(62.5 \%)$, xylometazoline $(59.3 \%)$, metoclopramide $(57.4 \%)$, metformin (53.8\%), cholecalciferol, doxycycline, estriol, formoterol, 
Table 2 Included substances, associated annual prescriptions in the year 2018, dosage forms, and strengths ${ }^{\mathrm{a}}$

\begin{tabular}{|c|c|c|c|}
\hline $\begin{array}{l}\text { Substance/ingredient } \\
\text { combination }\end{array}$ & $\begin{array}{l}\text { Annual prescriptions } \\
\left(\mathrm{x} 10^{6}\right)\end{array}$ & Dosage form & Strength \\
\hline Ibuprofen & 26.2 & Film-coated tablet & $600 \mathrm{mg}$ \\
\hline Metamizole & 25.6 & Oral drops & $500 \mathrm{mg} / \mathrm{ml}$ \\
\hline Pantoprazole & 21.1 & Gastro-resistant (enteric-coated) tablet & $40 \mathrm{mg}$ \\
\hline Ramipril & 20.2 & Tablet & $5 \mathrm{mg}$ \\
\hline Bisoprolol & 16.9 & Film-coated tablet & $5 \mathrm{mg}$ \\
\hline Metoprolol & 16.8 & Sustained-release tablet & $47,5 \mathrm{mg}$ \\
\hline Amlodipin & 13.4 & Tablet & $5 \mathrm{mg}$ \\
\hline Simvastatin & 12.5 & Film-coated tablet & $20 \mathrm{mg}$ \\
\hline Torasemide & 11.2 & Tablet & $10 \mathrm{mg}$ \\
\hline Metformin & 9.2 & Film-coated tablet & $1000 \mathrm{mg}$ \\
\hline Candesartan & 8.1 & Tablet & $16 \mathrm{mg}$ \\
\hline Acetyl salicilic acid & 7.0 & Tablet & $100 \mathrm{mg}$ \\
\hline Atorvastatin & 6.9 & Film-coated tablet & $40 \mathrm{mg}$ \\
\hline Diclofenac & 6.6 & Hard capsule & $75 \mathrm{mg}$ \\
\hline Salbutamol & 6.5 & Compressed gas inhalation / suspension & $0,12 \mathrm{mg} / \mathrm{puff}$ \\
\hline Omeprazole & 6.2 & Gastro-resistant (enteric-coated) hard capsule & $20 \mathrm{mg}$ \\
\hline Allopurinol & 6.1 & Tablet & $300 \mathrm{mg}$ \\
\hline Prednisolone & 6.0 & Tablet & $5 \mathrm{mg}$ \\
\hline Amoxicillin & 6.0 & Film-coated tablet & $500 \mathrm{mg}$ \\
\hline Xylometazoline & 5.6 & Nasal drops / spray & $1 \mathrm{mg} / \mathrm{ml}$ \\
\hline Tilidine / naloxone & 5.4 & Sustanied-release tablet & $50 \mathrm{mg} / 4 \mathrm{mg}$ \\
\hline Valsartan & 4.6 & Film-coated tablet & $160 \mathrm{mg}$ \\
\hline Ramipril / hydrochlorothiazide & 4.4 & Tablet & $5 \mathrm{mg} / 25 \mathrm{mg}$ \\
\hline Cefuroxime & 4.1 & Film-coated tablet & $500 \mathrm{mg}$ \\
\hline Hydrochlorothiazide & 4.0 & Tablet & $25 \mathrm{mg}$ \\
\hline Pregabalin & 3.9 & Hard capsule & $75 \mathrm{mg}$ \\
\hline Tamsulosin & 3.8 & Hard capsule & $0,4 \mathrm{mg}$ \\
\hline Lecarnidipine & 3.4 & Film-coated tablet & $10 \mathrm{mg}$ \\
\hline Apixaban & 3.2 & Film-coated tablet & $5 \mathrm{mg}$ \\
\hline Paracetamol & 3.2 & Suppositories & $75 \mathrm{mg}$ \\
\hline Enalapril & 3.2 & Tablet & $10 \mathrm{mg}$ \\
\hline Insulin glargine & 3.1 & Solution for injection (pre-mixed pen) & $300 \mathrm{IU}$ \\
\hline Mirtazapine & 3.1 & Film-coated tablet & $15 \mathrm{mg}$ \\
\hline Candesartan / hydrochlorothiazide & 3.1 & Tablet & $16 \mathrm{mg} / 12,5 \mathrm{mg}$ \\
\hline Colecalciferol & 3.1 & Soft capsule & $20 \mathrm{mg}$ \\
\hline Citalopram & 2.8 & Film-coated tablet & $20 \mathrm{mg}$ \\
\hline Ciprofloxacin & 2.8 & Film-coated tablet & $500 \mathrm{mg}$ \\
\hline Azithromycin & 2.8 & Film-coated tablet & $500 \mathrm{mg}$ \\
\hline Tramadol & 2.8 & Sustained-release tablet & $100 \mathrm{mg}$ \\
\hline Levodopa / benserazide & 2.7 & Tablet & $100 \mathrm{mg} / 25 \mathrm{mg}$ \\
\hline Rivaroxaban & 2.6 & Film-coated tablet & $20 \mathrm{mg}$ \\
\hline Formoterol / Beclomethasone & 2.6 & Compressed gas inhalation, solution & $6 \mu \mathrm{g} / 100 \mu \mathrm{g}$ \\
\hline Quetiapin & 2.5 & Film-coated tablet & $25 \mathrm{mg}$ \\
\hline Phenprocoumon & 2.4 & Tablet & $3 \mathrm{mg}$ \\
\hline Sitagliptin & 2.4 & Film-coated tablet & $100 \mathrm{mg}$ \\
\hline Furosemide & 2.4 & Tablet & $40 \mathrm{mg}$ \\
\hline Moxonidine & 2.3 & Film-coated tablet & $0,2 \mathrm{mg}$ \\
\hline Zopiclone & 2.3 & Film-coated tablet & $7,5 \mathrm{mg}$ \\
\hline Metoclopramide & 2.3 & Tablet & $10 \mathrm{mg}$ \\
\hline
\end{tabular}


Table 2 (continued)

\begin{tabular}{|c|c|c|c|}
\hline $\begin{array}{l}\text { Substance/ingredient } \\
\text { combination }\end{array}$ & $\begin{array}{l}\text { Annual prescriptions } \\
\left(\mathrm{x} 10^{6}\right)\end{array}$ & Dosage form & Strength \\
\hline Venlafaxine & 2.2 & Sustained-release hard capsule & $75 \mathrm{mg}$ \\
\hline Enoxaparin & 2.2 & Soution for injection & $4000 \mathrm{IU}$ \\
\hline Spironolactone & 2.2 & Tablet & $50 \mathrm{mg}$ \\
\hline Valsartan / hydrochlorothiazide & 2.1 & Film-coated tablet & $160 \mathrm{mg} / 12,5 \mathrm{mg}$ \\
\hline Opipramol & 2.1 & Film-coated tablet & $50 \mathrm{mg}$ \\
\hline Amoxicillin / clavulanic acid & 2.0 & Film-coated tablet & $875 \mathrm{mg} / 125 \mathrm{mg}$ \\
\hline Lorazepam & 1.9 & Tablet & $1 \mathrm{mg}$ \\
\hline Nebivolol & 1.9 & Tablet & $5 \mathrm{mg}$ \\
\hline Metformin / sitagliptin & 1.9 & Film-coated tablet & $1000 \mathrm{mg} / 50 \mathrm{mg}$ \\
\hline Amitriptyline & 1.9 & Film-coated tablet & $25 \mathrm{mg}$ \\
\hline Dexamethasone / gentamicin & 1.9 & Eye drops & $1 \mathrm{mg} / 5 \mathrm{mg}$ \\
\hline Doxycycline & 1.9 & Tablet & $100 \mathrm{mg}$ \\
\hline Estriol & 1.9 & Vaginal creme & $1 \mathrm{mg}$ \\
\hline Clindamycin & 1.9 & Film-coated tablet & $600 \mathrm{mg}$ \\
\hline Etoricoxib & 1.9 & Tablet & $90 \mathrm{mg}$ \\
\hline Lisinopril & 1.9 & Tablet & $10 \mathrm{mg}$ \\
\hline Ofloxacin & 1.9 & Eye drops & $3 \mathrm{mg}$ \\
\hline Risperidone & 1.8 & Film-coated tablet & $0,5 \mathrm{mg}$ \\
\hline Macrogol & 1.8 & Powder for oral solution & $13,125 \mathrm{~g}$ \\
\hline Fentanyl & 1.8 & Transdermal patch & $5,78 \mathrm{mg}(25 \mu \mathrm{g} / \mathrm{h})$ \\
\hline Fosfomycin & 1.8 & Granulate for oral solution & $3000 \mathrm{mg}$ \\
\hline Phenoxymethylpenicillin & 1.8 & Film-coated tablet & $980,4 \mathrm{mg}$ \\
\hline Gabapentin & 1.8 & Hard capsule & $300 \mathrm{mg}$ \\
\hline Mometasone & 1.7 & Nasal drops / spray & $0,052 \mathrm{mg}(50 \mu \mathrm{g} / \mathrm{spray})$ \\
\hline Clopidogrel & 1.7 & Film-coated tablet & $75 \mathrm{mg}$ \\
\hline Ivy leaves & 1.7 & Oral solution & $7 \mathrm{mg} / \mathrm{ml}$ \\
\hline Human insulin & 1.7 & Solution for injection & $300 \mathrm{IU}$ \\
\hline Budesonide & 1.7 & Powder for inhaltion & $0,2 \mathrm{mg}$ \\
\hline Salmeterol / fluticasone & 1.7 & Powder for inhalation & $50 \mu \mathrm{g} / 500 \mu \mathrm{g}$ \\
\hline Carvedilol & 1.7 & Tablet & 25 \\
\hline Methylphenidate & 1.7 & Hard capsule & 20 \\
\hline Insulin lispro & 1.6 & Solution for injection & $300 \mathrm{IU}$ \\
\hline Insulin aspart & 1.6 & Solution for injection & $300 \mathrm{IU}$ \\
\hline Tiotropium bromide & 1.6 & Hard capsule with powder for inhalation & $18 \mu \mathrm{g}$ \\
\hline $\begin{array}{l}\text { Formoterol / } \\
\text { budesonide }\end{array}$ & 1.6 & Powder for inhalation & $9 \mu \mathrm{g} / 320 \mu \mathrm{g}$ \\
\hline Methocarbamol & 1.6 & Film-coated tablet & $750 \mathrm{mg}$ \\
\hline Melperone & 1.5 & Film-coated tablet & $25 \mathrm{mg}$ \\
\hline Betamethasone & 1.5 & Creme & $1,214 \mathrm{mg}$ \\
\hline Esomeprazole & 1.5 & Gastro-resistant (enteric-coated) tablet & $40 \mathrm{mg}$ \\
\hline Latanoprost & 1.5 & Eye drops & $0,05 \mathrm{mg}$ \\
\hline Levetiracetam & 1.5 & Film-coated tablet & $500 \mathrm{mg}$ \\
\hline Sulfamethoxazole / trimethoprim & 1.5 & Tablet & $800 \mathrm{mg} / 160 \mathrm{mg}$ \\
\hline Codeine & 1.4 & Tablet & $30 \mathrm{mg}$ \\
\hline Sertraline & 1.4 & Film-coated tablet & $50 \mathrm{mg}$ \\
\hline Escitalopram & 1.4 & Film-coated tablet & $10 \mathrm{mg}$ \\
\hline Mometasone & 1.4 & Creme & $1 \mathrm{mg}$ \\
\hline Formoterol & 1.3 & Hard capsule with powder for inhalation & $12,5 \mu \mathrm{g}$ \\
\hline Oxycodone & 1.3 & Sustained-release tablet & $10 \mathrm{mg}$ \\
\hline
\end{tabular}


Table 2 (continued)

\begin{tabular}{llll}
\hline $\begin{array}{l}\text { Substance/ingredient } \\
\text { combination }\end{array}$ & $\begin{array}{l}\text { Annual prescriptions } \\
\left(\mathrm{x} 10^{6}\right)\end{array}$ & Dosage form & Strength \\
\hline Zolpidem & 1.3 & Film-coated tablet & $10 \mathrm{mg}$ \\
Valproic acid & 1.3 & Sustained-release tablet & $300 \mathrm{mg}$ \\
Cefaclor & 1.3 & Granulate for oral solution & $250 \mathrm{mg}$ \\
\hline
\end{tabular}

$I U$ international unit

${ }^{a}$ presented in descending order by annual prescriptions referring to the year 2018 ( number of annual prescriptions of any of the available package sizes of a drug containing the respective substance)

lorazepam, sulfamethoxazole/trimethoprim (each $50 \%$ ), bisoprolol $(47.4 \%)$, oxycodone $(46.4 \%)$, lercanidipine, metoprolol, pantoprazole, penicillin (in each case $44.4 \%$ ), ibuprofen $(42.9 \%)$, and human insulin (40\%).

Table 5 demonstrates number of evaluated same-substance SmPCs, number of listed Inds (and mean, median, maximum and minimum number of Inds, standard deviation), and absolute and relative frequencies of drugs/SmPCs with discrepancies in the number of CInds.

\section{Other formal and content-related discrepancies in the presentation of CInds (secondary analysis)}

A discrepancy of type A was found in 25 SmPCs referring to 13 active substances (13\%), type B in five SmPCs referring to four active substances (4\%), and type $\mathrm{C}$ in 40 SmPCs referring to 13 active substances (13\%). Twentyseven SmPCs referring to ten active substances (10\%) featured a discrepancy of type D. Two types of discrepancies in one SmPC (combined type) were found in eight active substances $(8 \%)$ referring to $17 \mathrm{SmPCs}$. For details see Table 6.

\section{Discussion}

In the present study, the SmPCs of the one hundred most frequently prescribed active substances in Germany in the year 2018 were analyzed for discrepancies in the presentation of Inds and CInds. We found considerable proportions of included active substances with differing same-substance SmPCs: $41 \%$ respectively $65 \%$ of the active substances had same-substance SmPCs that differed in the number of listed Inds respectively CInds from the reference SmPC. In addition, we found many active substances with remarkably large proportions of same-substance SmPCs $(>50 \%)$ that diverged from the respective reference $\mathrm{SmPC}$, particularly in the number of CInds. The number of listed Inds/CInds varied considerably between same-substance SmPCs with maximum ranges regarding Inds of 7 in amoxicillin, and CInds of 11 in lisinopril. Other discrepancies which refer to the wording and/or position of the respective Inds/CInds in the SmPC were also analyzed in order to contextualize the primary findings of discrepancies in the mere number of Inds and CInds. Here, we also found considerable proportions of active substances that featured same-substance SmPCs with formal and contentrelated differences other than the discrepancy in the number of Inds and CInds. To summarize, this evaluation of same-substance SmPCs demonstrates a clear lack of harmonization of same-substance SmPCs.

Taken into account that generic substitution has become the rule [2] and the physician usually does not know which drug the patient receives in the pharmacy, the discrepancies between same-substance SmPCs found in our study raise several questions, particularly regarding informed consent and medical liability. Indeed, the standards of the aut-idem substitution in Germany are pursuing safe drug treatment in generic substitution by ensuring the substitution of only nearly "identical products". Nevertheless, differences between substitutable same-substance drugs in regulatory aspects and/or pharmacologic/galenic properties (e.g., approved indications, excipients, additives, carriers of the drug, dosage form, appearance and size of the drug, bioavailability etc.) are permitted. It should be considered that switching from brand-name to generic medication may be associated with reduced efficacy and tolerability, and differences in bioequivalence, particularly regarding psychoactive drugs, as shown in several studies [3-9]. Given the large number of same-substance drugs that can be mutually exchanged in the pharmacy and the volatility of the generic drug market, the physician is virtually incapable of being sufficiently aware of the discrepancies between same-substance drugs and/or SmPCs. How can the physician then attend to his duty of informed consent? Who is legally responsible in the case of damage due to adverse 
Table 3 Discrepancies between same-substance SmPCs in the number of listed indications ${ }^{\mathrm{a}}$

\begin{tabular}{|c|c|c|c|c|c|c|c|c|}
\hline \multirow[b]{2}{*}{ Substance / ingredient combination } & \multirow[b]{2}{*}{$\begin{array}{l}\text { Number of } \\
\text { evaluated } \\
\text { SmPCs }\end{array}$} & \multicolumn{6}{|c|}{ Number of listed indications } & \multirow[b]{2}{*}{$\begin{array}{l}\text { Absolute and relative } \\
\text { frequencies of divergent } \\
\text { SmPCs }\end{array}$} \\
\hline & & $\begin{array}{l}\text { Arithmetic } \\
\text { mean }\end{array}$ & Median & Min & Max & Range & SD & \\
\hline Amoxicillin & 10 & 13.7 & 14 & 9 & 16 & 7 & 1.8 & $2(20 \%)$ \\
\hline Ibuprofen & 21 & 5.6 & 6 & 2 & 7 & 5 & 1.2 & $4(19 \%)$ \\
\hline Allopurinol & 15 & 6.1 & 6 & 5 & 9 & 4 & 0.8 & $2(13.3 \%)$ \\
\hline Clopidogrel & 42 & 6.7 & 7 & 3 & 7 & 4 & 0.9 & $8(19 \%)$ \\
\hline Trimethorpim / sulfamethoxazole & 8 & 9.4 & 9.5 & 7 & 11 & 4 & 1.7 & $5(62.5 \%)$ \\
\hline Escitalopram & 20 & 4.8 & 5 & 1 & 5 & 4 & 0.9 & $1(5 \%)$ \\
\hline Ramipril & 19 & 4.8 & 5 & 1 & 5 & 4 & 0.9 & $1(5.3 \%)$ \\
\hline Sertraline & 25 & 4.7 & 5 & 1 & 5 & 4 & 1.1 & $2(8 \%)$ \\
\hline Acetyl salicilic acid & 12 & 4.5 & 5 & 2 & 5 & 3 & 1.2 & $2(16.7 \%)$ \\
\hline Amoxicillin / clavulanic acid & 21 & 8.1 & 8 & 8 & 11 & 3 & 0.7 & $1(4.8 \%)$ \\
\hline Omeprazole & 27 & 9.7 & 10 & 7 & 10 & 3 & 0.8 & $3(11.1 \%)$ \\
\hline Amitriptyline & 4 & 4.5 & 5 & 3 & 5 & 2 & 1.0 & $1(25 \%)$ \\
\hline Betamethasone & 8 & 1.8 & 1 & 1 & 3 & 2 & 1.0 & $3(37.5 \%)$ \\
\hline Bisoprolol & 19 & 2.3 & 2 & 1 & 3 & 2 & 0.7 & $9(47.4 \%)$ \\
\hline Esomeprazole & 7 & 4.7 & 5 & 3 & 5 & 2 & 0.8 & $1(14.3 \%)$ \\
\hline Formoterol & 8 & 2.8 & 2.5 & 2 & 4 & 2 & 0.9 & $4(50 \%)$ \\
\hline Levodopa / benserazide & 7 & 2.1 & 2 & 1 & 3 & 2 & 0.7 & $3(42.9 \%)$ \\
\hline Metoclopramide & 7 & 2.4 & 3 & 1 & 3 & 2 & 1.0 & $2(28.6 \%)$ \\
\hline Prednisolone & 9 & 52.3 & 53 & 51 & 53 & 2 & 1.0 & $3(33.3 \%)$ \\
\hline Risperidone & 28 & 3.7 & 4 & 2 & 4 & 2 & 0.7 & $4(14.3 \%)$ \\
\hline Torasemide & 13 & 1.3 & 1 & 1 & 3 & 2 & 0.8 & $2(15.4 \%)$ \\
\hline Venlafaxine & 29 & 4.9 & 5 & 3 & 5 & 2 & 0.5 & $2(6.9 \%)$ \\
\hline Budesonide & 5 & 1.8 & 2 & 1 & 2 & 1 & 0.4 & $1(20 \%)$ \\
\hline Candesartan & 24 & 3.0 & 3 & 2 & 3 & 1 & 0.2 & $1(4.2 \%)$ \\
\hline Cefaclor & 7 & 4.9 & 5 & 4 & 5 & 1 & 0.4 & $1(14.3 \%)$ \\
\hline Ciprofloxacin & 17 & 19.8 & 20 & 19 & 20 & 1 & 0.4 & $4(23.5 \%)$ \\
\hline Citalopram & 25 & 1.6 & 2 & 1 & 2 & 1 & 0.5 & $9(36 \%)$ \\
\hline Codeine & 3 & 1.3 & 1 & 1 & 2 & 1 & 0.6 & $1(33.3 \%)$ \\
\hline Ivy leaves & 13 & 1.7 & 2 & 1 & 2 & 1 & 0.5 & $4(30.8 \%)$ \\
\hline Hydrochlorothiazide & 18 & 4.6 & 5 & 4 & 5 & 1 & 0.5 & $7(38.9 \%)$ \\
\hline Lisinopril & 19 & 3.9 & 4 & 3 & 4 & 1 & 0.3 & $2(10.5 \%)$ \\
\hline Lorazepam & 6 & 2.8 & 3 & 2 & 3 & 1 & 0.4 & $1(16.7 \%)$ \\
\hline Macrogol & 13 & 1.5 & 1 & 1 & 2 & 1 & 0.5 & $6(46.2 \%)$ \\
\hline Metoprolol & 18 & 7.9 & 8 & 7 & 8 & 1 & 0.3 & $2(11.1 \%)$ \\
\hline Mometasone & 6 & 1.5 & 1.5 & 1 & 2 & 1 & 0.5 & $3(50 \%)$ \\
\hline Pantoprazole & 45 & 3.9 & 4 & 3 & 4 & 1 & 0.3 & $3(6.7 \%)$ \\
\hline Penicillin & 9 & 6.9 & 7 & 6 & 7 & 1 & 0.3 & $1(11 \%)$ \\
\hline Pregabalin & 32 & 3.0 & 3 & 2 & 3 & 1 & 0.3 & $3(9.4 \%)$ \\
\hline Salbutamol & 10 & 1.8 & 2 & 1 & 2 & 1 & 0.4 & $2(20 \%)$ \\
\hline Salmeterol / Fluticason & 12 & 1.8 & 2 & 1 & 2 & 1 & 0.4 & $2(16.7 \%)$ \\
\hline Valproic acid & 15 & 2.5 & 3 & 2 & 3 & 1 & 0.5 & $7(46.7 \%)$ \\
\hline Amlodipine & 27 & 3.0 & 3 & 3 & 3 & 0 & 0 & 0 \\
\hline Apixaban & 4 & 3.0 & 3 & 3 & 3 & 0 & 0 & 0 \\
\hline Atorvastatin & 25 & 2.0 & 2 & 2 & 2 & 0 & 0 & 0 \\
\hline Azithromycin & 13 & 7.0 & 7 & 7 & 7 & 0 & 0 & 0 \\
\hline Candesartan / hydrochlorothiazide & 21 & 1.0 & 1 & 1 & 1 & 0 & 0 & 0 \\
\hline Carvedilol & 14 & 3.0 & 3 & 3 & 3 & 0 & 0 & 0 \\
\hline
\end{tabular}


Table 3 (continued)

\begin{tabular}{|c|c|c|c|c|c|c|c|c|}
\hline \multirow[b]{2}{*}{ Substance / ingredient combination } & \multirow[b]{2}{*}{$\begin{array}{l}\text { Number of } \\
\text { evaluated } \\
\text { SmPCs }\end{array}$} & \multicolumn{6}{|c|}{ Number of listed indications } & \multirow[b]{2}{*}{$\begin{array}{l}\text { Absolute and relative } \\
\text { frequencies of divergent } \\
\text { SmPCs }\end{array}$} \\
\hline & & $\begin{array}{l}\text { Arithmetic } \\
\text { mean }\end{array}$ & Median & Min & $\operatorname{Max}$ & Range & $\overline{\mathrm{SD}}$ & \\
\hline Cefuroxime & 13 & 8.0 & 8 & 8 & 8 & 0 & 0 & 0 \\
\hline Cholecalciferol & 4 & 1.0 & 1 & 1 & 1 & 0 & 0 & 0 \\
\hline Clindamycin & 9 & 7.0 & 7 & 7 & 7 & 0 & 0 & 0 \\
\hline Dexamethasone / gentamicin & 3 & 2.0 & 2 & 2 & 2 & 0 & 0 & 0 \\
\hline Diclofenac & 6 & 6.0 & 6 & 6 & 6 & 0 & 0 & 0 \\
\hline Doxycycline & 12 & 9.0 & 9 & 9 & 9 & 0 & 0 & 0 \\
\hline Enalapril & 19 & 3.0 & 3 & 3 & 3 & 0 & 0 & 0 \\
\hline Enoxaparin & 2 & 5.0 & 5 & 5 & 5 & 0 & 0 & 0 \\
\hline Estriol & 4 & 1.0 & 1 & 1 & 1 & 0 & 0 & 0 \\
\hline Etoricoxib & 21 & 5.0 & 5 & 5 & 5 & 0 & 0 & 0 \\
\hline Fentanyl & 6 & 2.0 & 2 & 2 & 2 & 0 & 0 & 0 \\
\hline Formoterol / beclomethasone & 4 & 2.0 & 2 & 2 & 2 & 0 & 0 & 0 \\
\hline Formoterol / budesonide & 6 & 2.0 & 2 & 2 & 2 & 0 & 0 & 0 \\
\hline Fosfomycin & 6 & 1.0 & 1 & 1 & 1 & 0 & 0 & 0 \\
\hline Furosemide & 15 & 5.0 & 5 & 5 & 5 & 0 & 0 & 0 \\
\hline Gabapentin & 27 & 3.0 & 3 & 3 & 3 & 0 & 0 & 0 \\
\hline Human insulin & 5 & 1.0 & 1 & 1 & 1 & 0 & 0 & 0 \\
\hline Insulin aspart & 5 & 1.0 & 1 & 1 & 1 & 0 & 0 & 0 \\
\hline Inuslin glargine & 3 & 1.0 & 1 & 1 & 1 & 0 & 0 & 0 \\
\hline Inuslin lispro & 3 & 1.0 & 1 & 1 & 1 & 0 & 0 & 0 \\
\hline Latanoprost & 18 & 4.0 & 4 & 4 & 4 & 0 & 0 & 0 \\
\hline Lercanidipine & 9 & 1.0 & 1 & 1 & 1 & 0 & 0 & 0 \\
\hline Levetiracetam & 25 & 4.0 & 4 & 4 & 4 & 0 & 0 & 0 \\
\hline Melperone & 9 & 3.0 & 3 & 3 & 3 & 0 & 0 & 0 \\
\hline Metamizole & 12 & 5.0 & 5 & 5 & 5 & 0 & 0 & 0 \\
\hline Metformin & 26 & 1.0 & 1 & 1 & 1 & 0 & 0 & 0 \\
\hline Metformin / sitagliptin & 2 & 4.0 & 4 & 4 & 4 & 0 & 0 & 0 \\
\hline Methocarbamol & 8 & 1.0 & 1 & 1 & 1 & 0 & 0 & 0 \\
\hline Methylphenidate & 6 & 1.0 & 1 & 1 & 1 & 0 & 0 & 0 \\
\hline Mirtazapin & 20 & 1.0 & 1 & 1 & 1 & 0 & 0 & 0 \\
\hline Mometasone & 8 & 2.0 & 2 & 2 & 2 & 0 & 0 & 0 \\
\hline Moxonidine & 12 & 1.0 & 1 & 1 & 1 & 0 & 0 & 0 \\
\hline Nebivolol & 12 & 2.0 & 2 & 2 & 2 & 0 & 0 & 0 \\
\hline Ofloxacin & 6 & 1.0 & 1 & 1 & 1 & 0 & 0 & 0 \\
\hline Opipramol & 15 & 2.0 & 2 & 2 & 2 & 0 & 0 & 0 \\
\hline Oxycodone & 28 & 1.0 & 1 & 1 & 1 & 0 & 0 & 0 \\
\hline Paracetamol & 3 & 2.0 & 2 & 2 & 2 & 0 & 0 & 0 \\
\hline Phenprocoumon & 5 & 3.0 & 3 & 3 & 3 & 0 & 0 & 0 \\
\hline Quetiapin & 21 & 2.0 & 2 & 2 & 2 & 0 & 0 & 0 \\
\hline Ramipril / hydrochlorothiazide & 18 & 1.0 & 1 & 1 & 1 & 0 & 0 & 0 \\
\hline Rivaroxaban & 8 & 3.0 & 3 & 3 & 3 & 0 & 0 & 0 \\
\hline Simvastatin & 32 & 2.0 & 2 & 2 & 2 & 0 & 0 & 0 \\
\hline Sitagliptin & 6 & 7.0 & 7 & 7 & 7 & 0 & 0 & 0 \\
\hline Spironolactone & 11 & 2.0 & 2 & 2 & 2 & 0 & 0 & 0 \\
\hline Tamsulosine & 28 & 1.0 & 1 & 1 & 1 & 0 & 0 & 0 \\
\hline Tilidine / naloxone & 8 & 2.0 & 2 & 2 & 2 & 0 & 0 & 0 \\
\hline Tiotropiumbromide & 3 & 1.0 & 1 & 1 & 1 & 0 & 0 & 0 \\
\hline
\end{tabular}


Table 3 (continued)

\begin{tabular}{|c|c|c|c|c|c|c|c|c|}
\hline \multirow[b]{2}{*}{ Substance / ingredient combination } & \multirow[b]{2}{*}{$\begin{array}{l}\text { Number of } \\
\text { evaluated } \\
\text { SmPCs }\end{array}$} & \multicolumn{6}{|c|}{ Number of listed indications } & \multirow[b]{2}{*}{$\begin{array}{l}\text { Absolute and relative } \\
\text { frequencies of divergen } \\
\text { SmPCs }\end{array}$} \\
\hline & & $\begin{array}{l}\text { Arithmetic } \\
\text { mean }\end{array}$ & Median & Min & Max & Range & $\mathrm{SD}$ & \\
\hline Tramadole & 20 & 1.0 & 1 & 1 & 1 & 0 & 0 & 0 \\
\hline Valsartan & 23 & 3.0 & 3 & 3 & 3 & 0 & 0 & 0 \\
\hline Valsartan / hydrochlorothiazide & 26 & 1.0 & 1 & 1 & 1 & 0 & 0 & 0 \\
\hline Xylometazoline & 27 & 1.0 & 1 & 1 & 1 & 0 & 0 & 0 \\
\hline Zolpidem & 20 & 1.0 & 1 & 1 & 1 & 0 & 0 & 0 \\
\hline Zopiclone & 18 & 1.0 & 1 & 1 & 1 & 0 & 0 & 0 \\
\hline
\end{tabular}

max maximum value, min minimum value, $S D$ standard deviation, $S m P C$ summary of product characteristics

a presented in descending order by the range

drug reactions or insufficient therap response that could have been avoided in the case of adequate information and individualized selection of a product? These aspects require a separate legal evaluation. Moreover, regulatory efforts appear necessary in order to improve harmonization of same-substance SmPCs.

\section{Limitations}

The extent of the analyzed data did not allow a contentrelated evaluation of the identified discrepancies. Therefore, we cannot determine, if the discrepancies found in our study correspond to real differences between the included same-substance drugs in regulatory aspects (e.g., different approved indications) and/or pharmacologic/galenic properties or merely represent errors in particular SmPCs (e.g., insufficient updating, production error). In this respect it has to be considered that the clinical relevance of the discrepancies found in our study remains unclear and requires. An adequate evaluation of the clinical relevance of these discrepancies requires a thorough analysis of contents and qualitative aspects of the diverging same-substance SmPCs. Furthermore, it is reasonable to assume that discrepancies between same-substance SmPCs are more common and of greater clinical importance for drugs approved by the national procedure, or by mutual recognition, than by the central procedure. Since we did not collect data on the type of approval procedure and the year of first approval of the included drugs, we are not able to provide evidence for this assumption. In addition, considering the volatility of the generic drug market and that SmPCs are subject to continuous adjustment, our results exclusively represent the SmPC-situation during the period of the data collection. Finally, we have evaluated SmPCs of drugs approved in Germany. Taken into account countrydependent differences in regulatory frameworks and drug markets, our results cannot be easily transferred to other countries. Therefore, it is unclear if the quantitative and qualitative discrepancies of same-substance SmPCs demonstrated by our analysis can be found in other countries.

Table 4 Other formal and content-related discrepancies between same-substance SmPCs in the presentation of indications

\begin{tabular}{llll}
\hline Substance / ingredient combination & $\begin{array}{l}\text { Number of evaluated } \\
\text { SmPCs }\end{array}$ & $\begin{array}{l}\text { Absolute and relative frequency of } \\
\text { SmPCs with discrepancy of type A }\end{array}$ & $\begin{array}{l}\text { Absolute and relative frequency of } \\
\text { SmPCs with discrepancy of type B }\end{array}$ \\
\hline Amoxicillin & 10 & 0 & $1(10 \%)$ \\
Levodopa / benzerazide & 7 & $1(14.3 \%)$ & 0 \\
Amoxicillin / clavulanic acid & 21 & 0 & $1(4.8 \%)$ \\
Sulfamethoxazole / trimethoprim & 8 & 0 & $1(12.5 \%)$ \\
\hline
\end{tabular}

SmPC summary of product characteristics 
Table 5 Discrepancies between same-substance SmPCs in the number of listed contraindications ${ }^{\mathrm{a}}$

\begin{tabular}{|c|c|c|c|c|c|c|c|c|}
\hline \multirow[b]{2}{*}{ Substance / ingredient combination } & \multirow[b]{2}{*}{$\begin{array}{l}\text { Number of } \\
\text { evaluated } \\
\text { SmPCs }\end{array}$} & \multicolumn{6}{|c|}{ Number of listed contraindications } & \multirow[b]{2}{*}{$\begin{array}{l}\text { Absolute and relative } \\
\text { frequencies of divergent } \\
\text { SmPCs }\end{array}$} \\
\hline & & Arithmetic mean & Median & Min & Max & Range & $\mathrm{SD}$ & \\
\hline Lisinopril & 19 & 7.5 & 7 & 5 & 16 & 11 & 2.7 & $7(36.8 \%)$ \\
\hline Hydrochlorothiazide & 18 & 9.1 & 9 & 2 & 11 & 9 & 1.9 & $7(38.9 \%)$ \\
\hline Torasemide & 13 & 7.0 & 7 & 5 & 13 & 8 & 2.8 & $8(61.5 \%)$ \\
\hline Carvedilol & 14 & 14.1 & 15 & 10 & 17 & 7 & 2.8 & $10(71.4 \%)$ \\
\hline Betamethasone & 8 & 11.1 & 10.5 & 9 & 15 & 6 & 1.9 & $5(62.5 \%)$ \\
\hline Formoterol & 8 & 2.3 & 2 & 1 & 7 & 6 & 2.0 & $4(50 \%)$ \\
\hline Lorazepam & 6 & 5.8 & 7.5 & 2 & 8 & 6 & 3.0 & $3(50 \%)$ \\
\hline Metoprolol & 18 & 15.0 & 16 & 10 & 16 & 6 & 1.5 & $8(44.4 \%)$ \\
\hline Oxycodone & 28 & 6.8 & 7 & 6 & 12 & 6 & 1.1 & $13(46.4 \%)$ \\
\hline Mometasone & 6 & 11 & 11 & 9 & 13 & 4 & 1.4 & $4(66.7 \%)$ \\
\hline Doxycyclin & 12 & 4.5 & 5 & 3 & 6 & 3 & 1.1 & $6(50 \%)$ \\
\hline Estriol & 4 & 8.5 & 8.5 & 7 & 10 & 3 & 1.7 & $2(50 \%)$ \\
\hline Lercanidipine & 9 & 11.9 & 13 & 10 & 13 & 3 & 1.5 & $4(44.4 \%)$ \\
\hline Metformin & 26 & 7.0 & 7 & 6 & 9 & 3 & 1.0 & $14(53.8 \%)$ \\
\hline Metoclopramide & 7 & 10.7 & 11 & 9 & 12 & 3 & 1.3 & $4(57.4 \%)$ \\
\hline Risperidone & 28 & 1.2 & 1 & 1 & 4 & 3 & 0.6 & $4(14.3 \%)$ \\
\hline Spironolactone & 11 & 9.2 & 9 & 8 & 11 & 3 & 1.0 & $4(36.4 \%)$ \\
\hline Tramadol & 20 & 5.4 & 5 & 5 & 8 & 3 & 0.8 & $6(30 \%)$ \\
\hline Trimethoprim / sulfamethoxazole & 8 & 9.9 & 10 & 8 & 11 & 3 & 1.0 & $4(50 \%)$ \\
\hline Xylometazoline & 27 & 4.6 & 5 & 3 & 6 & 3 & 0.6 & $16(59.3 \%)$ \\
\hline Allopurinol & 15 & 2.6 & 3 & 1 & 3 & 2 & 0.8 & $3(20 \%)$ \\
\hline Amlodipine & 27 & 5.1 & 5 & 5 & 7 & 2 & 0.5 & $2(7.4 \%)$ \\
\hline Bisoprolol & 19 & 12.5 & 12 & 12 & 14 & 2 & 0.6 & $9(47.4 \%)$ \\
\hline Cefaclor & 7 & 4.4 & 4 & 4 & 6 & 2 & 0.8 & $2(28.6 \%)$ \\
\hline Cholecalciferol & 4 & 7.3 & 7.5 & 6 & 8 & 2 & 1.0 & $2(50 \%)$ \\
\hline Codeine & 3 & 10.3 & 11 & 9 & 11 & 2 & 1.2 & $1(33.3 \%)$ \\
\hline Enalapril & 19 & 6.6 & 7 & 5 & 7 & 2 & 0.7 & $7(36.8 \%)$ \\
\hline Human insuline & 5 & 1.8 & 1 & 1 & 3 & 2 & 1.1 & $2(40 \%)$ \\
\hline Metamizole & 12 & 6.3 & 6 & 6 & 8 & 2 & 0.8 & $2(16.7 \%)$ \\
\hline Omeprazole & 27 & 2.1 & 2 & 2 & 4 & 2 & 0.4 & $2(7.4 \%)$ \\
\hline Simvastatin & 32 & 5.5 & 6 & 4 & 6 & 2 & 0.8 & $10(31.3 \%)$ \\
\hline Valproic acid & 15 & 8.9 & 9 & 8 & 10 & 2 & 0.5 & $3(20 \%)$ \\
\hline Valsartan / hydrochlorothiazide & 26 & 6.0 & 6 & 5 & 7 & 2 & 0.4 & $5(19.2 \%)$ \\
\hline Amitriptyline & 4 & 7.3 & 7 & 7 & 8 & 1 & 0.5 & $1(25 \%)$ \\
\hline Atorvastatin & 25 & 4.1 & 4 & 4 & 5 & 1 & 0.4 & $2(8 \%)$ \\
\hline Azitromycin & 13 & 4.3 & 4 & 4 & 5 & 1 & 0.5 & $4(30.8 \%)$ \\
\hline Budesonide & 5 & 1.8 & 2 & 1 & 2 & 1 & 0.5 & $1(20 \%)$ \\
\hline Candesartan & 24 & 5.0 & 5 & 4 & 5 & 1 & 0.2 & $1(4.2 \%)$ \\
\hline Candesartan/hydrochlorothiazide & 21 & 9.0 & 9 & 8 & 9 & 1 & 0.2 & $1(4.8 \%)$ \\
\hline Cefuroxim & 13 & 3.2 & 3 & 3 & 4 & 1 & 0.4 & $2(15.4 \%)$ \\
\hline Citalopram & 25 & 5.1 & 5 & 5 & 6 & 1 & 0.3 & $3(12 \%)$ \\
\hline Clopidogrel & 42 & 3.1 & 3 & 3 & 4 & 1 & 0.2 & $2(4.8 \%)$ \\
\hline Ivy leaves & 13 & 1.8 & 2 & 1 & 2 & 1 & 0.4 & $2(15.4 \%)$ \\
\hline Formoterol/budesonide & 6 & 1.8 & 2 & 1 & 2 & 1 & 0.4 & $1(16.7 \%)$ \\
\hline Fosfomycin & 6 & 2.3 & 2 & 2 & 3 & 1 & 0.5 & $2(33 \%)$ \\
\hline Gabapentin & 27 & 1.0 & 1 & 1 & 2 & 1 & 0.2 & $1(3.7 \%)$ \\
\hline Ibuprofen & 21 & 10.6 & 11 & 10 & 11 & 1 & 0.5 & $9(42.9 \%)$ \\
\hline
\end{tabular}


Table 5 (continued)

\begin{tabular}{|c|c|c|c|c|c|c|c|c|}
\hline \multirow[b]{2}{*}{ Substance / ingredient combination } & \multirow[b]{2}{*}{$\begin{array}{l}\text { Number of } \\
\text { evaluated } \\
\text { SmPCs }\end{array}$} & \multicolumn{6}{|c|}{ Number of listed contraindications } & \multirow[b]{2}{*}{$\begin{array}{l}\text { Absolute and relative } \\
\text { frequencies of divergent } \\
\text { SmPCs }\end{array}$} \\
\hline & & Arithmetic mean & Median & Min & Max & Range & $\mathrm{SD}$ & \\
\hline Levodopa / benserazide & 7 & 12.1 & 12 & 12 & 13 & 1 & 0.4 & $1(14.3 \%)$ \\
\hline Melperone & 9 & 5.7 & 6 & 5 & 6 & 1 & 0.5 & $3(33 \%)$ \\
\hline Methocarbamol & 8 & 5.1 & 5 & 5 & 6 & 1 & 0.4 & $1(12.5 \%)$ \\
\hline Methylphenidate & 6 & 9.2 & 9 & 9 & 10 & 1 & 0.4 & $1(16.7 \%)$ \\
\hline Mirtazapine & 20 & 2.3 & 2 & 2 & 3 & 1 & 0.5 & $6(30 \%)$ \\
\hline Nebivolol & 12 & 11.1 & 11 & 11 & 12 & 1 & 0.3 & $1(8.3 \%)$ \\
\hline Opipramol & 15 & 9.7 & 10 & 9 & 10 & 1 & 0.5 & $4(26.7 \%)$ \\
\hline Pantoprazole & 45 & 1.4 & 1 & 1 & 2 & 1 & 0.5 & $20(44.4 \%)$ \\
\hline Penicillin & 9 & 3.6 & 4 & 3 & 4 & 1 & 0.5 & $4(44.4 \%)$ \\
\hline Ramipril & 19 & 7.9 & 8 & 7 & 8 & 1 & 0.3 & $2(10.5 \%)$ \\
\hline Ramipril / hydrochlorothiazide & 18 & 10.8 & 11 & 10 & 11 & 1 & 0.4 & $3(16.7 \%)$ \\
\hline Salbutamol & 10 & 1.3 & 1 & 1 & 2 & 1 & 0.5 & $3(30 \%)$ \\
\hline Selmeterol / fluticasone & 12 & 1.2 & 1 & 1 & 2 & 1 & 0.4 & $2(16.7 \%)$ \\
\hline Tiotropiumbromide & 3 & 1.3 & 1 & 1 & 2 & 1 & 0.6 & $1(33 \%)$ \\
\hline Valsartan & 23 & 4.1 & 4 & 4 & 5 & 1 & 0.3 & $2(8.7 \%)$ \\
\hline Venlaflaxine & 29 & 3.3 & 3 & 3 & 4 & 1 & 0.5 & $9(31 \%)$ \\
\hline Zolpidem & 20 & 5.4 & 5 & 5 & 6 & 1 & 0.5 & $7(35 \%)$ \\
\hline Zopiclone & 18 & 6.3 & 6 & 6 & 7 & 1 & 0.5 & $6(33.3 \%)$ \\
\hline Acetyl salicilic acid & 12 & 8.0 & 8 & 8 & 8 & 0 & 0 & 0 \\
\hline Amoxicillin & 10 & 2.0 & 2 & 2 & 2 & 0 & 0 & 0 \\
\hline Amoxicillin / clavulanic acid & 21 & 3.0 & 3 & 3 & 3 & 0 & 0 & 0 \\
\hline Apixaban & 4 & 5.0 & 5 & 5 & 5 & 0 & 0 & 0 \\
\hline Ciprofloxacin & 17 & 2.0 & 2 & 2 & 2 & 0 & 0 & 0 \\
\hline Clindamycin & 9 & 2.0 & 2 & 2 & 2 & 0 & 0 & 0 \\
\hline Dexamethasone / gentamicin & 3 & 7.0 & 7 & 7 & 7 & 0 & 0 & 0 \\
\hline Diclofenac & 6 & 11.0 & 11 & 11 & 11 & 0 & 0 & 0 \\
\hline Enoxaparin & 2 & 4.0 & 4 & 4 & 4 & 0 & 0 & 0 \\
\hline Escitalopram & 20 & 5.0 & 5 & 5 & 5 & 0 & 0 & 0 \\
\hline Esomeprazole & 7 & 3.0 & 3 & 3 & 3 & 0 & 0 & 0 \\
\hline Etoricoxib & 21 & 11.0 & 11 & 11 & 11 & 0 & 0 & 0 \\
\hline Fentanyl & 6 & 6.0 & 6 & 6 & 6 & 0 & 0 & 0 \\
\hline Formoterol/Beclomethason & 4 & 1.0 & 1 & 1 & 1 & 0 & 0 & 0 \\
\hline Furosemide & 15 & 8.0 & 8 & 8 & 8 & 0 & 0 & 0 \\
\hline Insulin aspart & 5 & 1.0 & 1 & 1 & 1 & 0 & 0 & 0 \\
\hline Insulin lispro & 3 & 2.0 & 2 & 2 & 2 & 0 & 0 & 0 \\
\hline Insulin glargine & 3 & 1.0 & 1 & 1 & 1 & 0 & 0 & 0 \\
\hline Latanoprost & 18 & 1.0 & 1 & 1 & 1 & 0 & 0 & 0 \\
\hline Levetiracetam & 25 & 2.0 & 2 & 2 & 2 & 0 & 0 & 0 \\
\hline Macrogol & 13 & 4.0 & 4 & 4 & 4 & 0 & 0 & 0 \\
\hline Metformin / sitagliptin & 2 & 14.0 & 14 & 14 & 14 & 0 & 0 & 0 \\
\hline Mometasone & 8 & 3.0 & 3 & 3 & 3 & 0 & 0 & 0 \\
\hline Moxonidine & 12 & 5.0 & 5 & 5 & 5 & 0 & 0 & 0 \\
\hline Ofloxacin & 6 & 2.0 & 2 & 2 & 2 & 0 & 0 & 0 \\
\hline Paracetamol & 3 & 1.0 & 1 & 1 & 1 & 0 & 0 & 0 \\
\hline Phenprocoumon & 5 & 8.0 & 8 & 8 & 8 & 0 & 0 & 0 \\
\hline Prednisolone & 9 & 1.0 & 1 & 1 & 1 & 0 & 0 & 0 \\
\hline Pregabalin & 32 & 1.0 & 1 & 1 & 1 & 0 & 0 & 0 \\
\hline
\end{tabular}


Table 5 (continued)

\begin{tabular}{lllllllll}
\hline & & \multicolumn{2}{l}{ Number of listed contraindications } & & & \\
\cline { 2 - 8 } Substance / ingredient combination & $\begin{array}{l}\text { Number of } \\
\text { evaluated } \\
\text { SmPCs }\end{array}$ & Arithmetic mean & Median & Min & Max & Range & $\begin{array}{l}\text { SD } \\
\text { Absolute and relative } \\
\text { frequencies of divergent } \\
\text { SmPCs }\end{array}$ \\
\hline Quetiapine & 21 & 2.0 & 2 & 2 & 2 & 0 & 0 & 0 \\
Rivaroxaban & 8 & 6.0 & 6 & 6 & 6 & 0 & 0 & 0 \\
Sertraline & 25 & 3.0 & 3 & 3 & 3 & 0 & 0 & 0 \\
Sitagliptin & 6 & 1.0 & 1 & 1 & 1 & 0 & 0 & 0 \\
Tamsulosin & 28 & 3.0 & 3 & 3 & 3 & 0 & 0 & 0 \\
Tilidine / naloxone & 8 & 6.0 & 6 & 6 & 6 & 0 & 0 & 0 \\
\hline
\end{tabular}

max maximum value, min minimum value, $S D$ standard deviation, $S m P C$ summary of product characteristics

a presented in descending order by the range

Table 6 Other formal and content-related discrepancies between same-substance SmPCs in the presentation of contraindications ${ }^{\mathrm{a}}$

\begin{tabular}{|c|c|c|c|c|c|c|}
\hline \multirow[b]{2}{*}{ Substance / ingredient combination } & \multirow[b]{2}{*}{$\begin{array}{l}\text { Number of evaluated } \\
\text { SmPCs }\end{array}$} & \multicolumn{5}{|c|}{ Absolute and relative frequency of SmPCs with discrepancy of ... } \\
\hline & & Type A & Type B & Type $C^{b}$ & Type D & Combined type ${ }^{b}$ \\
\hline Metamizole & 12 & 0 & 0 & 0 & $2(16.7 \%)$ & 0 \\
\hline Bisoprolol & 19 & 0 & $1(5.3 \%)$ & 0 & 0 & $1^{\mathrm{B}+\mathrm{D}}(5.3 \%)$ \\
\hline Metoprolol & 18 & 0 & 0 & $\begin{array}{l}5^{1 \mathrm{a}}(27.8 \%) \\
1^{2 \mathrm{~b}}(5.6 \%)\end{array}$ & 0 & 0 \\
\hline Simvastatin & 32 & 0 & 0 & $\begin{array}{l}1^{1 \mathrm{~b}}(3.1 \%) \\
6^{2 \mathrm{~b}}(18.8 \%)\end{array}$ & 0 & $1^{\mathrm{B}+\mathrm{C} 2 \mathrm{~b}}(3.1 \%)$ \\
\hline Torasemide & 13 & 0 & 0 & $5^{1 \mathrm{a}+\mathrm{b}}(38.5 \%)$ & $1(7.7 \%)$ & 0 \\
\hline Metformin & 26 & $1(3.8 \%)$ & 0 & 0 & $3(11.5 \%)$ & $3^{\mathrm{B}+\mathrm{D}}(11.5 \%)$ \\
\hline Omeprazole & 27 & 0 & $1(3.7 \%)$ & 0 & 0 & 0 \\
\hline Allopurinol & 15 & 0 & 0 & $3^{1 \mathrm{~b}}(20 \%)$ & 0 & 0 \\
\hline Hydrochlorothiazide & 18 & 0 & 0 & $1^{2 \mathrm{a}+\mathrm{b}}(5.6 \%)$ & $2(11.1 \%)$ & 0 \\
\hline Tramadole & 20 & 0 & 0 & 0 & $5(25 \%)$ & 0 \\
\hline Levodopa / benserazide & 7 & 0 & 0 & 0 & $1(14.3 \%)$ & 0 \\
\hline Phenprocoumon & 5 & $2(40 \%)$ & 0 & 0 & 0 & 0 \\
\hline Zopiclone & 18 & 0 & 0 & 0 & $4(22.2 \%)$ & 0 \\
\hline Metoclopramide & 7 & $1(14.3 \%)$ & 0 & 0 & 0 & 0 \\
\hline Spironolactone & 11 & 0 & 0 & $2^{1 . b}(18.2 \%)$ & 0 & 0 \\
\hline Valsartan / hydrochlorothiazide & 26 & $1(3.8 \%)$ & 0 & 0 & 0 & 0 \\
\hline Lorazepam & 6 & 0 & 0 & $2^{1 \mathrm{a}+\mathrm{b}}(33.3 \%)$ & 0 & $1^{\mathrm{B}+\mathrm{Clb}}(16.7 \%)$ \\
\hline Amitriptyline & 4 & 0 & 0 & 0 & 0 & $1^{\mathrm{B}+\mathrm{C} 2 \mathrm{~b}}(25 \%)$ \\
\hline Doxycyclin & 12 & $2(16.7 \%)$ & 0 & $4^{1 \mathrm{~b}}(33.3 \%)$ & 0 & 0 \\
\hline Estriol & 4 & 0 & 0 & 0 & 0 & $2^{\mathrm{B}+\mathrm{C} 2 \mathrm{~b}}(50 \%)$ \\
\hline Fosfomycin & 6 & $1(16.7 \%)$ & 0 & 0 & 0 & 0 \\
\hline Penicillin & 9 & 0 & 0 & $2^{1 \mathrm{a}}(22.2 \%)$ & 0 & 0 \\
\hline Ivy leaves & 13 & $5(38.5 \%)$ & 0 & $2^{1 \mathrm{~b}}(15.4 \%)$ & 0 & 0 \\
\hline Salmeterol / fluticasone & 12 & 0 & 0 & 0 & $2(16.7 \%)$ & 0 \\
\hline Carvedilol & 14 & 0 & 0 & $3^{2 \mathrm{~b}}(21.4 \%)$ & 0 & $7^{\mathrm{B}+\mathrm{C} 2 \mathrm{~b}}(50 \%)$ \\
\hline Tiotropium bromide & 3 & 0 & 0 & 0 & $1(33.3 \%)$ & 0 \\
\hline Betamethasone & 8 & $3(37.5 \%)$ & 0 & 0 & 0 & $1^{\mathrm{B}+\mathrm{Cla}}(12.5 \%)$ \\
\hline Trimethoprim / sulfamethoxazole & 8 & $1(12.5 \%)$ & $2(25 \%)$ & 0 & 0 & 0 \\
\hline Codeine & 3 & $2(66.7 \%)$ & 0 & 0 & 0 & 0 \\
\hline Mometasone & 6 & $1(16.7 \%)$ & $1(16.7 \%)$ & 0 & 0 & 0 \\
\hline Formoterol & 8 & 0 & 0 & $2^{1 \mathrm{a}}(25 \%)$ & 0 & 0 \\
\hline Oxycodone & 28 & $2(7.1 \%)$ & 0 & 0 & 0 & 0 \\
\hline
\end{tabular}


Table 6 (continued)

Absolute and relative frequency of SmPCs with discrepancy of ...

\begin{tabular}{lllllll} 
Substance / ingredient combination & $\begin{array}{l}\text { Number of evaluated } \\
\text { SmPCs }\end{array}$ & Type A & Type B & Type $\mathrm{C}^{\mathrm{b}}$ & Type D & Combined type $^{\mathrm{b}}$ \\
\hline Zolpidem & 20 & 0 & 0 & 0 & $6(30 \%)$ & 0 \\
Valproic acid & 15 & 0 & 0 & $1^{1 \mathrm{~b}}(6.7 \%)$ & 0 & 0 \\
Cefaclor & 7 & $3(42.9 \%)$ & 0 & 0 & 0 & 0 \\
\hline
\end{tabular}

SmPC summary of product characteristics

${ }^{a}$ presented in descending order by the number of annual prescriptions (exact figures are presented in Table 1)

${ }^{b}$ The superscript letters and numbers behind the absolute frequencies (e.g., ${ }^{\text {la }}$ or ${ }^{\mathrm{B}+\mathrm{D}}$ ) indicate the respective subtype of discrepancy of type $\mathrm{C}$ or combination of two types of discrepancies; see Table 1 for definitions of types and subtypes of discrepancies

\section{Conclusions}

There are considerable discrepancies in the number of listed indications and contraindications between SmPCs of drugs with the same active ingredient. Further studies should address content-related aspects of these discrepancies. Nevertheless, our findings raise questions regarding informed consent and medical liability, which require a separate legal evaluation. Regulatory efforts appear necessary to improve the harmonization of samesubstance SmPCs.

\section{Acknowledgements None.}

Authors' contribution All authors contributed to the study conception and design. MG planned, conceptualized, and initialized the study, interpreted the data and wrote the first draft of the manuscript; BJC conceptualized the study, interpreted the data, and corrected the manuscript; RM conceptualized the study, interpreted the data, performed statistical analyses, and corrected the manuscript; RZ conceptualized the study, interpreted the data, and corrected the manuscript; AW planned and conceptualized the study, prepared the material, collected, analyzed, and interpreted the data, and corrected the manuscript.

Funding Open Access funding enabled and organized by Projekt DEAL. No funding was received for this study.

Availability of data and material The data evaluated in this study is available upon request. Please contact the corresponding author.

Code availability All analyses were performed with Microsoft Excel (version 2019).

\section{Declarations}

Conflict of interest/Competing interests The authors declare that they do not have any conflicts of interest.

Ethics approval No personal data was used in the present study. According to the guidelines and regulations of the local ethics committee (Ulm University) no ethical approval is necessary in such cases.

Consent to participate Not applicable.
Consent for publication All authors read and approved the submitted version of the manuscript and agreed to publish the submitted version of the manuscript.

Open Access This article is licensed under a Creative Commons Attribution 4.0 International License, which permits use, sharing, adaptation, distribution and reproduction in any medium or format, as long as you give appropriate credit to the original author(s) and the source, provide a link to the Creative Commons licence, and indicate if changes were made. The images or other third party material in this article are included in the article's Creative Commons licence, unless indicated otherwise in a credit line to the material. If material is not included in the article's Creative Commons licence and your intended use is not permitted by statutory regulation or exceeds the permitted use, you will need to obtain permission directly from the copyright holder. To view a copy of this licence, visit http://creativecommons.org/licenses/by/4.0/.

\section{References}

1. Korzilius H (2002) Aut-idem-Regelung: Unglückliche Umstände. Dtsch Arztebl 99(13):A822-A824

2. Schwabe U, Paffrath D, Ludwig W, Klauber J (eds) (2019) Arzneiverordnungs-Report 2019. Springer, Berlin

3. Margolese H, Wolf Y, Desmarais J, JE, Beauclair L (2010) Loss of response after switching from brand name to generic formulations: three cases and a discussion of key clinical considerations when switching. Int Clin Psychopharmacol 25(3):180-182

4. Cesak G, Rokita K, Dabowska M, Sejbuk-Rozbicka K, Zaremba A, Mirowska-Guzel D, Balkowiec-Iskra E (2016) Therapeutic equivalence of antipsychotics and antidepessants - A systematic review. Pharmacol Rep 68(2):217-223

5. Desmarais J, Beauclair L, Margolese H (2011) Switching from brand-name to generic psychotropic medications: a literature review. CNS Neuro Sci Ther 17(6):750-760

6. Carbon M, Correll C (2013) Rational use of generic psychotropic drugs. CNS Drugs 27(5):353-365

7. Borgheini G (2003) The bioequivalence and therapeutic efficacy of generic versus brand-name psychoactive drugs. Clin Ther 25(6): 1578-1592

8. Holtkamp M, Theodore W (2018) Generic antiepileptic drugs-Safe or harmful in patients with epilepsy? Epilepsia 59(7):1273-1281

9. Cheng N, Rahman M, Alatawi Y, Qian J, Peissig P, Berg R, Page C, Hansen R (2018) Mixed approach retrospective analysis of suicide and suicidal ideation for brand compared with generic central nervous system drugs. Drug Saf 41(4):363-376 
10. Shimazawa R, Kano Y, Ikeda M (2018) Natural language processing-based assessment of consistency in summaries of product characteristics. Pharmacol Res Perspect 6(6):e00435

11. Freudenmann R, Freudenmann N, Zurowski B, SchönfeldtLecuona C, Maier L, Schmieder R, Lange-Asschenfeldt C, Gahr M (2017) Arterial Hyper- and Hypotension associated with psychiatric medications: a risk assessment based on the summaries of product characteristics (SmPCs). Dtsch Med Wochenschr 142(16): e100-e107

12. Gahr M, Freudenmann R, Connemann B, Schönfeldt-Lecuona C, Muche R, Hiemke C, Sillmann Y (2020) Different number of contraindications between summaries of product characteristics (SmPCs) of drugs with the same active ingredients - an analysis of data of neuropsychiatric drugs. Fortschr Neurol Psychiatr 88(3):152-169

13. Thoenes A, Cariolato L, Spierings J, Pincon A (2020) Discrepancies between the labels of originator and generic products: implications for patient safety. Drugs Real World Outcome 7(2):131-139

14. EMA (2018) QRD general principles regarding the SmPC information for a generic/hybrid/biosimilar product. Available at: https:// www.ema.europa.eu/en/documents/regulatory-procedural-guideline/ quality-review-documents-general-principles-regarding-summaryproduct-characteristics-information/hybrid/biosimilar-product_en. pdf. (Accessed 22 Aug 2021)

15. EMA. Referral procedures. Available at: https://www.ema. europa.eu/en/human-regulatory/post-authorisation/referral-proce dures. (Accessed 22 Aug 2021)

16. EMA. How to prepare and review a summary of product characteristics. Available at: https://www.ema.europa.eu/human-regulatory/ marketing-authorisation/product-information/how-prepare-reviewsummary-product-characteristics. (Accessed 22 Aug 2021)

17. GBA (2018) Anlage VII zum Abschnitt M der Arzneimittel-Richtlinie. Regelungen zur Austauschbarkeit von Arzneimitteln (autidem). Available at: https://www.g-ba.de/downloads/83-691-627/ AM-RL-VII_Aut-idem_2020-11-15.de. (Accessed 22 Aug 2021)

18. DIMDI (Ed.) (2017) Anatomisch-therapeutisch-chemische Klassifikation mit Tagesdosen

Publisher's Note Springer Nature remains neutral with regard to jurisdictional claims in published maps and institutional affiliations. 